\title{
Lower serum osteocalcin is associated with more severe metabolic syndrome in elderly men from the MINOS cohort
}

\author{
Cyrille B Confavreux, Pawel Szulc, Romain Casey', Annie Varennes², \\ Joelle Goudable ${ }^{3}$ and Roland D Chapurlat
}

INSERM U1033 - Université de Lyon, Department of Rheumatology, Hôpital Edouard Herriot, Hospices Civils de Lyon, Lyon, 69003 France, 'OFSEP-Université de Lyon, France Hospices Civils de Lyon, Lyon, 69003 France,

${ }^{2}$ Université de Lyon, Central Biochemical Laboratory, Hôpital Edouard Herriot, Hospices Civils de Lyon, Lyon, 69003 France and ${ }^{3}$ INSERM U1060 - Université de Lyon, Lyon, France

Correspondence should be addressed to C B Confavreux

Email

cyril.confavreux@inserm.fr

\begin{abstract}
Background: Bone has emerged as an endocrine organ regulating energy metabolism through secretion of osteocalcin. In epidemiological studies, presence of metabolic syndrome (MetS) was associated with lower osteocalcin level.

Objectives: We evaluated whether osteocalcin level was associated with MetS severity in men and whether it was more strongly associated with MetS compared with $\mathrm{N}$-terminal propeptide of type I procollagen (PINP), bone-specific alkaline phosphatase (BAP), and C-terminal telopeptide of type I collagen ( $\beta C T X)$.

Methods: We included 798 men aged 51-85 years for total osteocalcin measurement. Number of MetS criteria was used to define severity. We used polytomous logistic regression to assess the relationship between MetS severity and osteocalcin level.

Results: Thirty percent of men had MetS. In patients with MetS, the higher the number of MetS traits were present, the lower was the average osteocalcin level (0-2 criteria: 551 men: $19.5 \pm 6.7 \mathrm{ng} / \mathrm{ml}$, three criteria: $155 \mathrm{men}: 19.3 \pm 7.4 \mathrm{ng} / \mathrm{ml}$, four criteria: 72 men: $17.3 \pm 5.7 \mathrm{ng} / \mathrm{ml}$, and five criteria: $20 \mathrm{men}: 15.0 \pm 5.1 \mathrm{ng} / \mathrm{ml} ; P$ for trend=0.002).

In the polytomous logistic regression model, an increase in osteocalcin level of $10 \mathrm{ng} / \mathrm{ml}$ was associated with lower prevalence of severe MetS: three criteria (odds ratio $(O R)=0.93(0.70-1.24)$ ), four criteria $(O R=0.54(0.34-0.84)$ ), and five criteria $(\mathrm{OR}=0.28(0.10-0.82)$ ) in comparison with no MetS ( $P$ for trend $=0.008)$.

After adjustment, using stepwise analysis of the polytomous logistic regression model, we observed that osteocalcin, age, and apparent free testosterone entered in the model but not other bone markers (PINP, $\beta C T X$, and BAP).

Conclusion: In older Caucasian men, total osteocalcin level was associated with MetS severity. Osteocalcin was more strongly associated with MetS severity than other bone turnover markers.
\end{abstract}

\section{Introduction}

The metabolic syndrome (MetS) is a common metabolic disorder corresponding to the association of several cardiovascular risk factors in one individual $(1,2)$. In Western countries, the prevalence of MetS is estimated to be between 34 and 39\% of the population (3). Underlying genetic susceptibility may explain prevalence variations of MetS among ethnic groups (4). Prevalence of MetS has
European Journal of

Endocrinology

(2014) 171, 275-283
(ㄷ) 2014 European Society of Endocrinology Printed in Great Britain been rising all around the world. It is favored by the burst of obesity due to the increased prevalence of high-fat diets combined with the general decrease in physical activity (5). Thus, MetS has recently become a major public health issue around the world, because it is associated with a doubling cardiovascular event risk and a 10-year cardiovascular mortality. This risk is even higher in patients with 
MetS and type II diabetes $(6,7,8)$. Standard care relies on body weight loss, lifestyle modifications, physical activity, and control of other cardiovascular risk factors such as tobacco consumption. In the onset of MetS, one of the key pathophysiological mechanisms involved is the increase in insulin resistance associated with an excess of circulating fatty acid and low adiponectin (1).

In 2007, a new function of bone was evidenced with the discovery that the bone-specific protein, called osteocalcin, was a hormone acting on energy metabolism (9). Osteocalcin is synthesized by osteoblasts and released into blood. However, osteocalcin is secreted predominantly in carboxylated form with high affinity to bone matrix. Therefore, this fraction is embedded in bone matrix during bone formation as a stock waiting for its release upon bone resorption in an undercarboxylated active form (10). Osteocalcin functions as an upstream regulator of three key hormones involved in energy metabolism. Indeed, osteocalcin targets at least three organs: pancreas, where it promotes insulin secretion; adipocytes, where it stimulates adiponectin expression; and Leydig cells, to favor testosterone production $(11,12)$. After the observation of reduced insulin secretion and increased insulin resistance in Osteocalcin-deficient mice, serum osteocalcin level was found to be associated with HbA1c and type II diabetes in humans (13). On this basis, the implication of osteocalcin in humans was then extended to MetS $(14,15)$. Most of the available studies have reported an association between osteocalcin and the absence/presence of MetS. Nevertheless, data concerning MetS severity are scarce. One study was conducted in a population of young Chinese (16) and another one in a Chinese cohort at high cardiovascular risk (17). To our knowledge, there are no data on the link between osteocalcin level and MetS severity in Caucasian men. Moreover, there is no information whether osteocalcin is more strongly associated with MetS in comparison with other serum bone turnover markers. Thus, we wanted to test whether osteocalcin may be associated with MetS severity in a general study of Caucasian men and whether this association was stronger than the one observed with other bone turnover markers.

\section{Materials and methods}

\section{Description of the cohort}

The MINOS study is a cohort study of osteoporosis and its determinants in men (18). It is the result of a collaborative project involving INSERM and Société de Secours Minière de Bourgogne (SSMB), one of the largest local health insurance companies, which covers mineworkers and their families living in the French city of Montceau-les-Mines and its surrounding area. This area represents roughly 35000 inhabitants. The study was accepted by the local ethics committee and performed in accordance with the Declaration of Helsinki as revised in 1983. Among the 3400 random invitations sent to the men covered by SSMB in 1995-96, 841 men agreed to participate and 799 had a total serum osteocalcin measurement at baseline. One patient with active Paget bone disease was excluded and the current analysis was conducted on 798 men aged 51-85 years (Fig. 1). All participants provided informed consent.

In 1996, a non-response bias survey was conducted in 120 initially invited men to ensure that participants who did not respond were not different from those who accepted to participate. No differences in terms of education level, smoking, calcium, and alcohol intake, former professional and current leisure physical activity,

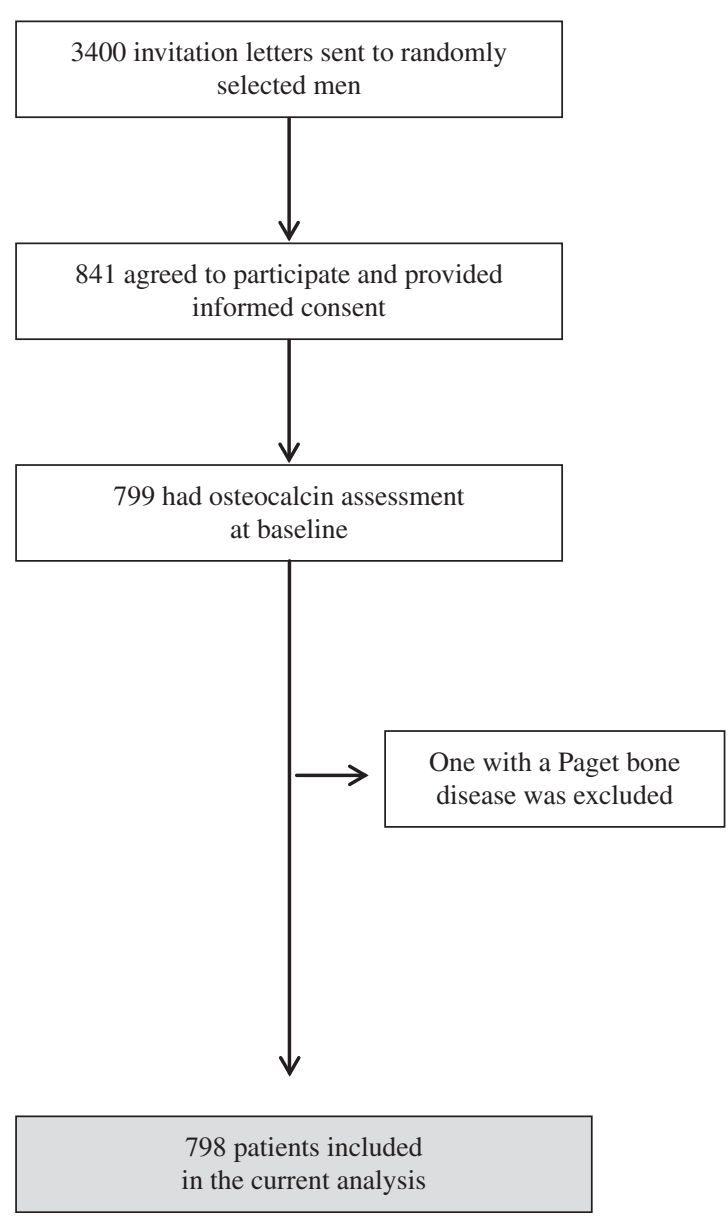

Figure 1

Flowchart of patient recruitment to the study. 
personal and family history of the fragility fracture, health status, and medication use were observed (19).

\section{Clinical data}

At enrolment, the lifestyle and health status of each patient were collected by epidemiological questionnaire. Cigarette smoking was self-reported and classified as 'never smokers' vs 'ever smokers' (i.e., former and current). Alcohol intake was quantified as the average quantity of alcoholic beverages drunk weekly. Physical activity (leisure sport activity, gardening, and walking) was calculated on the basis of the overall amount of time (h/month). Comorbidities (diabetes, hypertension, and ischemic heart disease) and current medication including vitamin $\mathrm{K}$ antagonists were self-reported and dichotomized as yes/no. We verified information using medical prescriptions and previous hospitalization reports. Body weight, height, and abdomen perimeter were measured by a single investigator (P S) according to a standardized procedure.

\section{Biochemical measurements}

Fasting blood samples were collected at baseline. All the samples were immediately centrifuged and then frozen. No measurements were performed using fresh blood samples. Serum samples were stored at $-80^{\circ} \mathrm{C}$ until measurements at 18-20 months. Serum calcium, phosphorus, albumin, and creatinine were assessed using standard laboratory methods. Glucose was measured by the hexokinase method (Modular Analyzer, Roche). Triglycerides (TGs) were measured by colorimetric test (Modular Analyzer, Roche). HDL-cholesterol was measured by homogenous enzymatic colorimetric test (Modular Analyzer, Roche). Bone resorption was assessed using serum levels of C-terminal telopeptide of type I collagen ( $\beta \mathrm{CTX}$ ) (Elecsys; Roche Diagnostic). Bone formation was assessed by bonespecific alkaline phosphatase (BAP) (Alkphase-B Metra Bio Systems, Inc., Mountain View, CA, USA) and N-terminal propeptide of type I procollagen (PINP) (Intact PINP, Farmos Diagnostica, Uppsala, Sweden). Serum total osteocalcin was measured with a human-specific, two-site IRMA (IRMA, ELSA-OSTEO; CIS Bio International, Bagnols sur Cèze, France). In addition, serum 25-hydroxycholecalciferol (25OHD) was measured by RIA, which excludes any interference with lipids (Incstar Corp., Stillwater, MN, USA). Serum total testosterone was measured by tritiated RIA after diethylether extraction. The apparent free testosterone concentration was calculated. Details about each method have been published previously (20).

\section{Definition of MetS}

We used the recently harmonized definition of MetS (21), requiring the presence of at least three abnormal findings among the following five criteria: elevated fasting glucose $(\geq 5.6 \mathrm{mmol} / \mathrm{l}$ ), elevated blood pressure (systolic $\geq 130 \mathrm{mmHg}$ and/or diastolic $\geq 85 \mathrm{mmHg}$ ), elevated TGs $(\geq 1.7 \mathrm{mmol} / \mathrm{l})$, reduced HDL-cholesterol $(<1.03 \mathrm{mmol} / \mathrm{l})$, and elevated waist circumference (European threshold: $\geq 102 \mathrm{~cm}$ ).

\section{Statistical analysis}

All calculations were performed using SAS 9.3 software version (SAS Institute, Inc., Cary, NC, USA). All $P$ values were calculated using two-tailed test, and values of $<0.05$ were considered significant. Normality for all parameters was checked on histograms and Q-Q plots. Distributions of blood PINP, BAP, glucose, and TG levels clearly deviate from normality. These variables were $\log$ transformed for correlation analysis. Categorical variables are presented as number (\%) and continuous variables as mean \pm s.D. or median (lower quartile, upper quartile) when appropriate.

Osteocalcin and blood glucose $\downarrow$ Simple bivariate correlation between osteocalcin and blood glucose was performed and secondarily adjusted for other variables correlated with osteocalcin using partial correlation method.

Metabolic syndrome $\downarrow$ Using $t$-tests, we performed twogroup comparisons of osteocalcin between men with or without each individual element of MetS and between men with or without MetS. Then, the association between the presence of MetS and osteocalcin was assessed using logistic regression adjusted for age, 25OHD, testosterone, physical activity (h/month), tobacco smoking (yes/no), and alcohol intake (quartiles of the average weekly intake). We checked that all the included continuous predictors displayed linear relationship with MetS. We did not include in the model BMI or hip-waist ratio because they were significantly correlated with the abdomen perimeter, already a criterion of MetS.

In addition, we added to the logistic model other bone markers (PINP, $\beta C T X$, and BAP) one by one and compared the fit of the models by likelihood ratio tests (LRT). If addition of one bone marker increased the fit of the model, we checked whether osteocalcin stays significant. 
Osteocalcin and MetS severity $>$ A comparison of osteocalcin levels across the number of components of MetS was made using ANOVA with post hoc analysis (TukeyKramer test).

We considered the number of MetS traits as ordinal variables and used a polytomous logistic regression model to assess the relationship between the severity of MetS and osteocalcin levels. A polytomous logistic regression is a regression model which generalizes logistic regression by allowing more than two discrete outcomes. It is a model that is used to predict the probabilities of the different possible outcomes of a categorically distributed dependent variable (here being severity of MetS), given a set of independent variables (here being osteocalcin level and adjustments variables). First, we tested the asumption of proportional odds, which assumes that the odds of response below a given response level are constant, regardless of which level is selected as the reference. Secondly, we used a generalized logit model in which one odds ratio (OR) for each modality of response variable was estimated. This model was adjusted for age, 25OHD, apparent free testosterone, physical activity, tobacco smoking, and alcohol intake.

In addition, we added to polytomous logistic model other bone markers (PINP, $\beta$ CTX, and BAP) one by one and compared the fit of the models by LRT. If addition of one bone marker increased the fit of the model, we checked whether osteocalcin stays significant. Furthermore, we performed a stepwise analysis of the polytomous logistic regression model.

\section{Results}

\section{Baseline characteristics}

At baseline, 798 men had osteocalcin measurements. No participant self-reported hyperthyroidism, primary hyperparathyroidism, or Cushing's disease at the time of recruitment. Their average age was 65.3 years and their average BMI was $28.0 \mathrm{~kg} / \mathrm{m}^{2}$ (Table 1). Nearly 25\% of the cohort self-reported high blood pressure, 15\% ischemic heart disease, and 7\% diabetes. More than two-thirds of men were current or former smokers.

\section{Correlations between serum osteocalcin and blood glucose}

In bivariate analysis, osteocalcin was negatively correlated with blood glucose $\left(r^{2}=0.04 ; P<0.0001\right)$. This association was in the same range as the positive one observed
Table 1 Baseline characteristics of the 798 men included in the MINOS cohort for which a valid osteocalcin assessment was available. Data are presented as mean \pm s.D., median (q1-q3) or $n(\%)$.

\begin{tabular}{|c|c|}
\hline Clinical parameters & Values \\
\hline Age (years) & $65 \pm 7$ \\
\hline $\mathrm{BMI}\left(\mathrm{kg} / \mathrm{m}^{2}\right)$ & $28 \pm 4$ \\
\hline Waist circumference $(\mathrm{cm})$ & $99.2 \pm 10.0$ \\
\hline Ischemic heart disease & $121(15.2)$ \\
\hline High blood pressure & $197(24.7)$ \\
\hline Diabetes & $58(7.3)$ \\
\hline Smoker & $538(67.4)$ \\
\hline \multicolumn{2}{|l|}{ Alcohol intake } \\
\hline No & $187(23.4)$ \\
\hline Occasional & $209(26.2)$ \\
\hline$<3 \mathrm{IU} / \mathrm{day}$ & $242(30.3)$ \\
\hline$\geq 3 \mathrm{IU} / \mathrm{day}$ & $159(19.9)$ \\
\hline \multicolumn{2}{|l|}{ Physical activity group } \\
\hline$<10 \mathrm{~h} / \mathrm{w}$ & $110(13.8)$ \\
\hline $10-20 \mathrm{~h} / \mathrm{w}$ & $276(34.6)$ \\
\hline $20-30 \mathrm{~h} / \mathrm{w}$ & $253(31.7)$ \\
\hline$>30 \mathrm{~h} / \mathrm{w}$ & $158(19.8)$ \\
\hline \multicolumn{2}{|l|}{ Biological parameters } \\
\hline Osteocalcin (ng/ml) & $19.2 \pm 6.8$ \\
\hline Blood glucose $(\mathrm{mmol} / \mathrm{l})$ & $5.7(5.4-6.3)$ \\
\hline Total cholesterol (mmol/l) & $5.9 \pm 1.0$ \\
\hline HDL-cholesterol (mmol/l) & $1.3 \pm 0.4$ \\
\hline Triglycerides $(\mathrm{mmol} / \mathrm{l})$ & $1.7(1.3-2.3)$ \\
\hline $25 \mathrm{OHD}(\mathrm{nmol} / \mathrm{l})$ & $70 \pm 30$ \\
\hline Apparent free testosterone (pmol/l) & $198.8 \pm 78.9$ \\
\hline$\beta C \mathrm{CTX}(\mathrm{mmol} / \mathrm{l})$ & $2.4 \pm 1.2$ \\
\hline Bone ALP (mIU/l) & $15.7(13.0-19.3)$ \\
\hline PINP (ng/ml) & $32.4(26.3-42.4)$ \\
\hline
\end{tabular}

250HD, 25-hydroxycholecalciferol; $\beta C T X, C$-terminal telopeptide of type I collagen; bone ALP, bone-specific alkaline phosphatase; PINP, N-terminal propeptide of type I procollagen.

between BMI and blood glucose $\left(r^{2}=0.07 ; P<0.0001\right)$. Osteocalcin was also significantly negatively correlated with BMI, physical activity, 25OHD, TGs, $17 \beta$-estradiol and positively correlated with hip-waist ratio and SHBG $\left(r^{2}=0.01\right.$ to $0.02 ; P<0.02$ to $\left.<0.001\right)$. Osteocalcin was not correlated with age, total cholesterol, and HDL-cholesterol $\left(r^{2}=0.0001\right.$ to $\left.0.0025 ; P>0.05\right)$. After adjustment for age, BMI, hip-waist ratio, physical activity, 25OHD, TGs, $17 \beta-$ estradiol, and SHBG, osteocalcin remained negatively correlated with blood glucose $\left(r^{2}=0.03 ; P<0.0001\right)$.

\section{Osteocalcin and MetS}

Thirty percent of the cohort had MetS based on the above definition. In bivariate comparison (Table 2), osteocalcin was lower in patients with MetS in comparison with normal men $(P=0.033)$. Interestingly, analysis of the link between osteocalcin and each criterion of MetS showed that osteocalcin was lower in men with elevated blood glucose $(\geq 5.6 \mathrm{mmol} / \mathrm{l})$ and marginally lower with an 
Table 2 Bivariate comparison of osteocalcin according to each diagnostic criteria of metabolic syndrome (MetS). Data are presented as mean \pm s.D. Student's $t$-test was performed to determine level of significant difference.

\begin{tabular}{|c|c|c|}
\hline & $n$ & $\begin{array}{l}\text { Osteocalcin } \\
\text { (ng/ml) }\end{array}$ \\
\hline \multicolumn{3}{|l|}{$\begin{array}{l}\text { Diagnostic criteria for MetS } \\
\text { Serum glucose }\end{array}$} \\
\hline Normal & 283 & $20.09 \pm 6.98$ \\
\hline $\begin{array}{l}\text { Elevated }(\geq 5.6 \mathrm{mmol} / \mathrm{l}) \\
P\end{array}$ & 494 & $\begin{array}{c}18.60 \pm 6.64 \\
0.0034\end{array}$ \\
\hline \multicolumn{3}{|l|}{ Blood pressure } \\
\hline Normal & 589 & $19.37 \pm 6.71$ \\
\hline Hypertension & 197 & $18.74 \pm 7.07$ \\
\hline$P$ & & 0.2582 \\
\hline \multicolumn{3}{|l|}{ Waist circumference } \\
\hline Normal & 552 & $19.46 \pm 6.82$ \\
\hline Elevated $(\geq 102 \mathrm{~cm})$ & 239 & $18.48 \pm 6.66$ \\
\hline$P$ & & 0.0636 \\
\hline \multicolumn{3}{|l|}{ Triglycerides } \\
\hline Normal & 396 & $19.51 \pm 6.70$ \\
\hline Elevated $(\geq 1.7 \mathrm{mmol} / \mathrm{l})$ & 381 & $18.77 \pm 6.89$ \\
\hline$P$ & & 0.1307 \\
\hline \multicolumn{3}{|l|}{ HDL cholesterol } \\
\hline Normal & 586 & $19.26 \pm 6.58$ \\
\hline Reduced $(<1.03 \mathrm{mmol} / \mathrm{l})$ & 191 & $18.79 \pm 7.44$ \\
\hline$P$ & & 0.4356 \\
\hline \multicolumn{3}{|l|}{ MetS } \\
\hline Absent & 551 & $19.50 \pm 6.73$ \\
\hline Present & 247 & $18.40 \pm 6.88$ \\
\hline$P$ & & 0.0334 \\
\hline
\end{tabular}

elevated waist circumference $(\geq 102 \mathrm{~cm})$. In the logistic regression model (Fig. 2), higher osteocalcin levels were associated with lower prevalence of MetS $(\mathrm{OR}=0.75$ per $10 \mathrm{ng} / \mathrm{ml}$ increase, 95\% CI: 0.58-0.97, which corresponds to $\mathrm{OR}=0.83$ per one s.D. increase, $95 \%$ CI: $0.70-0.98$; $P=0.028)$. A higher level of apparent free testosterone was also associated with a reduced risk of MetS $(\mathrm{OR}=0.70$ per $70 \mathrm{pmol} / \mathrm{l}$ increase, 95\% CI: 0.61-0.81, which corresponds to $\mathrm{OR}=0.67$ per one s.D. increase, $95 \%$ CI: $0.55-0.81$; $P<0.001)$.

\section{Osteocalcin, bone turnover markers, and MetS}

As expected, in bivariate analysis, we observed that correlations between osteocalcin and other bone turnover markers (BAP, PINP, and $\beta \mathrm{CTX}$ ) were high. Furthermore, we observed that the bone turnover markers were also associated with blood glucose and MetS (simple correlation coefficients were $r^{2}=0.008$ to $0.012 ; P<0.02$ to $<0.001)$ and that, in the forward stepwise logistic regression model, BAP entered into the model before osteocalcin. Thus, we wanted to test whether osteocalcin was more strongly associated with MetS compared with other bone markers. Bone markers (PINP, BAP, and $\beta \mathrm{CTX}$ ) were added one by one to the initial model including osteocalcin (as described above). The effect of the additional marker was assessed using LRT. The addition of PINP or $\beta C T X$ to the model did not increase its fit ( $P=0.44$ and $P=0.58$ respectively). The addition of BAP increased the fit of the model $(P=0.02)$, but osteocalcin stayed significant $(P=0.003)$.

\section{Osteocalcin and MetS severity}

In patients with MetS, the higher the number of the MetS traits present, the lower the average osteocalcin level was ( $P=0.002$ for global ANOVA) (Fig. 3).

In the analysis of the relationship between severity of MetS and osteocalcin, we tested the assumption of proportional odds of a polytomous regression model. Such an assumption was rejected $(P=0.022)$ indicating that the strength of the relationship between osteocalcin

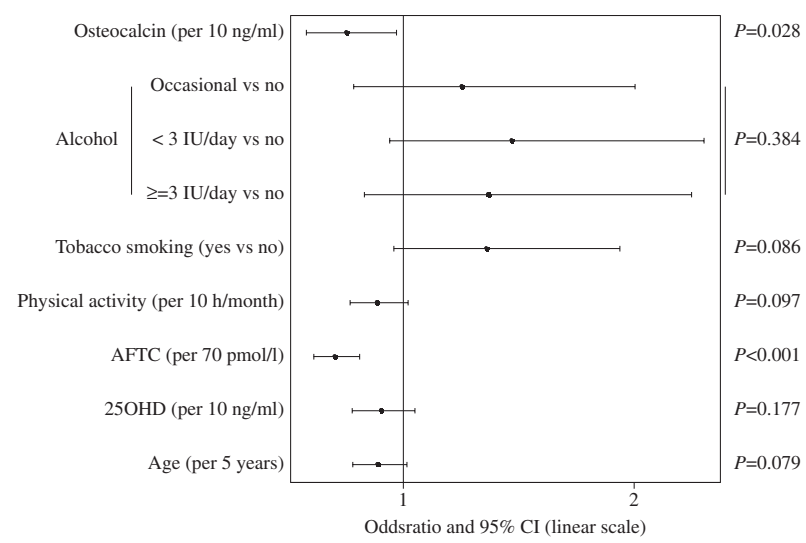

\section{Figure 2}

The figure displays the results of the logistic regression model assessing the association between the presence of MetS with all independent variables (osteocalcin, age, 250HD, testosterone, physical activity, tobacco smoking, and alcohol intake) introduced in the final multivariable model. All the OR presented in the figure are adjusted OR on all covariates of the model. OR are presented with increasing values for continuous variables: osteocalcin (per $10 \mathrm{ng} / \mathrm{ml}$ increase), physical activity (per $10 \mathrm{~h} /$ month increase), apparent free testosterone (AFTC) (per $70 \mathrm{pmol} / \mathrm{l}$ increase), $250 \mathrm{HD}$ (per $10 \mathrm{ng} / \mathrm{ml}$ increase), and age (per 5 years increase). Higher serum concentrations of osteocalcin were associated with a lower prevalence of metabolic syndrome $(\mathrm{OR}=0.75$ per $10 \mathrm{ng} / \mathrm{ml}$ increase, $95 \% \mathrm{Cl}: 0.58-0.97 ; P=0.028$ ). 


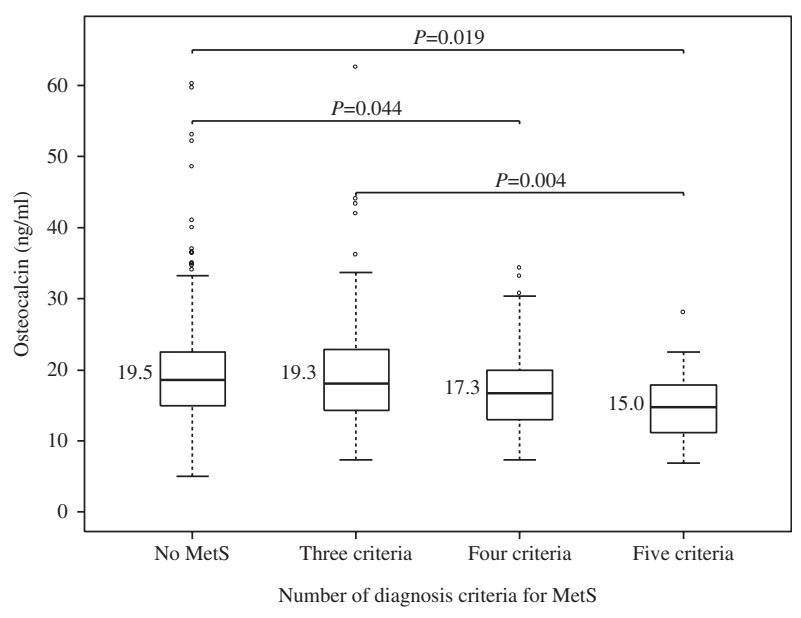

Figure 3

Association between serum osteocalcin levels and the number of MetS traits: no MetS $(n=551)$, three diagnosis criteria $(n=155)$, four criteria $(n=72)$, and five criteria $(n=20)$. Global ANOVA $P$ value was 0.002 . The figure displays significant $P$ values of the post hoc analysis between groups (Tukey-Kramer test).

levels and the probability of suffering from MetS with 'three criteria', 'four criteria' or 'five criteria' was different. Based on this result, we used a generalized logit model. After adjusting for confounders, we observed (Table 3) that the level of osteocalcin was associated with a lower prevalence of MetS in a stronger way when the severity of MetS increased $(P=0.008)$.

\section{Osteocalcin, bone turnover markers, and MetS severity}

The above model was compared with models of osteocalcin and each of bone turnover markers by LRT. We found that the addition of PINP, $\beta$ CTX, and BAP to the model did not improve its fit $(P=0.31, P=0.94$, and $P=0.12$ respectively). Furthermore, in the stepwise analysis of the polytomous logistic regression model adjusted for age, 25OHD, apparent free testosterone, physical activity, tobacco smoking, alcohol intake, and the other bone markers (PINP, $\beta$ CTX, and BAP), we observed that osteocalcin, age, and apparent free testosterone entered in the model but not other bone markers. This result suggested that osteocalcin was more strongly associated with MetS severity than the other bone turnover markers.

\section{Discussion}

In our cohort, we found that the higher the number of MetS criteria, the lower serum total osteocalcin was. Furthermore, MetS was associated with osteocalcin more strongly than with any other bone marker. In addition, the strength of the association between osteocalcin and MetS increased with the number of traits, thereby indicating that lower osteocalcin was associated with MetS severity in our population of older Caucasian men.

These results are clinically relevant because the severity of MetS, defined as the number of traits, is associated with the severity of subclinical atherosclerosis (22). It is also clinically relevant because we previously showed that baseline osteocalcin was associated with the progression rate of abdominal aortic calcification and 10-year overall survival (23). As severe abdominal aortic calcification is an intermediate criterion of cardiovascular morbidity and mortality in the general population $(24,25)$, it may be relevant to study whether low osteocalcin level is an independent indicator of higher cardiovascular risk in older men.

Moreover, our findings regarding the relationship between MetS and osteocalcin are consistent with the metabolic phenotype observed in mice lacking osteocalcin (9) or its receptor Gprc6a $(12,26)$. The initial phenotype description of osteocalcin-deficient mice highlighted that these mice were characterized by insulin resistance, overweight, and low insulin secretion (9). Soon afterwards, results from human studies indeed demonstrated

Table 3 Association between MetS severity and circulating osteocalcin after adjustment for age, 25OHD, apparent free testosterone, physical activity, smoking, and alcohol consumption using generalized logit model.

\begin{tabular}{|c|c|}
\hline & Metabolic syndrome \\
\hline & No \\
\hline $\begin{array}{l}\text { Osteocalcin } \\
\text { (per } 10 \mathrm{ng} / \mathrm{ml} \text { increase) }\end{array}$ & $\begin{array}{l}\text { Three criteria } \\
\text { Four criteria } \\
\text { Five criteria }\end{array}$ \\
\hline
\end{tabular}

\begin{tabular}{ccc}
\hline OR $(95 \% \mathrm{Cl})$ & \\
\hline Ref. & & $\boldsymbol{P}$ \\
\cline { 1 - 1 } $0.932(0.700-1.243)$ & & 0.620 \\
$0.539(0.341-0.842)$ & & 0.007 \\
$0.285(0.098-0.825)$ & 0.021 \\
\hline
\end{tabular}

Higher serum concentrations of osteocalcin were associated with severity of MetS ( $P$ for trend $=0.008)$ in a protective way: 10 ng/ml increase in osteocalcin level was associated with a lower prevalence of each category of MetS in comparison to no MetS. The association between osteocalcin and MetS was stronger with higher severity of MetS ( $P=0.022$ for assumption of proportional odds). 
that blood glucose, HbA1c, and adipokines, as well as elevated BMI or fat mass $(13,14,27,28,29)$, were associated with serum osteocalcin. Moreover, we have previously shown that after surgical resection of osteoid osteoma in young men, serum osteocalcin level decreased, whereas blood glucose increased, thereby providing the first direct evidence of the action of osteocalcin in humans (30).

Furthermore, our results are in line with those observed by Bao et al. (17) in a high-cardiovascular risk population of men who underwent coronary angiography. The latter also found an association between the decrease in osteocalcin and the increase in the number of MetS components. In a population-based study of older Caucasian men aged over 65 years, Saleem et al. (14) showed that osteocalcin was lower in patients with MetS and that low osteocalcin was associated with an increased prevalence of MetS. In aging men, results were confirmed in the Health in Men Study (15) and in the Longitudinal Aging Study Amsterdam (31). These studies did not analyze MetS severity. Only a study conducted in younger Chinese men (mean age of 40 years) showed a doseresponse relationship between MetS severity and serum osteocalcin levels. Participants with lower quartiles of serum osteocalcin had higher risk of more severe MetS (16). These results are consistent with our results. Interestingly, even if osteocalcin is implicated in the regulation of male fertility through the secretion of testosterone $(12,32)$, it seems that the action of osteocalcin on glucose metabolism and MetS is conserved and observed in both genders $(14,31,33,34)$. Furthermore, in addition to the study of Yeap (15) and to our work on a Caucasian population, research has also been conducted on other ethnic groups including Blacks (14), Chinese (16, 17), and Koreans (33), suggesting that osteocalcin metabolic functions initially discovered in rodents $(9,11,35,36)$ are conserved in humans and across ethnic groups. Lastly, a causal relationship in humans has been recently reported with the finding of MetS and primary testicular failure in patients with a genetic dominant-negative mutation of the osteocalcin receptor (GPRC6A) (32).

On the basis of these initial results, further investigations are needed to evaluate whether therapeutic interventions targeting osteocalcin may improve the severity of MetS or elements thereof. Currently, there is no drug available for humans to target osteocalcin or its receptors. In mice, recombinant osteocalcin has been successfully used to treat WT mice fed high-fat diet. This was first established with continuous infusion of osteocalcin through pumps (37) and confirmed with daily i.p. injections (38). In the daily injection protocol for instance, on normal chow, treatment by osteocalcin improved glucose tolerance and insulin sensitivity as well as increased insulin secretion which was accompanied by a significant expansion of the $\beta$-cell mass. Glucosestimulated insulin secretion test demonstrated that insulin secretion was dose-dependently increased. Next, following 2 months' high-fat diet induction of obesity, diabetes and liver steatosis, mice were allocated to receive osteocalcin daily injections or placebo. Osteocalcin treatment reduced body weight gain and improved glucose tolerance and insulin tolerance in comparison with placebo after 8 weeks of treatment. An increase in energy expenditure through high mitochondrial capacity was also observed. In addition, liver histological analysis after treatment revealed a disappearance of the steatosis (38). Human interventions to increase osteocalcin serum levels have been tested indirectly. In a pilot study in obese patients submitted to either an aerobic or a power acute exercise (39), the reduction in serum glucose post-acute exercise at $2 \mathrm{~h}$ was correlated with the percentage change of uncarboxylated osteocalcin, especially in the aerobic program. In addition, a post hoc analysis of the PaTH study (PTH 1-84 vs alendronate) showed that higher increase in uncarboxylated osteocalcin at 3 month was associated with higher increase in adiponectin and greater decrease in body weight and fat mass at 1 year (40). Common metabolic parameters, such as blood glucose and insulin, were not significantly associated but blood withdrawals were not done on morning fast samples. Altogether, the physiology observed in rodents, the continuous relationship observed in our study and the latter results of indirect intervention are very promising and provide a rationale to decipher the underlying mechanism of the action of osteocalcin on MetS in humans.

Our study has limitations. The cohort includes predominantly lower- and middle-class Caucasian men and the data cannot be extrapolated to women or to men from other ethnic groups. They were recruited in a small town and its population may not be representative of the general population in France. In addition, lifestyle factors were self-reported. As it is a cross-sectional study, causeeffect relationships cannot be firmly established. Finally, we did not measure undercarboxylated osteocalcin because our serum samples were collected more than 15 years ago.

In conclusion, our study shows that the level of total osteocalcin was associated with MetS severity in older Caucasian men. MetS severity was associated with osteocalcin more strongly than with any other bone 
markers, which suggests a specific link, independent from the general bone turnover rate.

\section{Declaration of interest}

The authors declare that there is no conflict of interest that could be perceived as prejudicing the impartiality of the research reported.

\section{Funding}

This research did not receive any specific grant from any funding agency in the public, commercial or not-for-profit sector.

\section{Acknowledgements}

The authors thank $M$ Zimmermann for critical reading of the manuscript. The authors dedicate this article to the memory of Prof. Christian Confavreux.

\section{References}

1 Eckel RH, Grundy SM \& Zimmet PZ. The metabolic syndrome. Lancet 2005365 1415-1428. (doi:10.1016/S0140-6736(05)66378-7)

2 Grundy SM. Metabolic syndrome: a multiplex cardiovascular risk factor. Journal of Clinical Endocrinology and Metabolism 200792 399-404. (doi:10.1210/jc.2006-0513)

3 Ford ES. Prevalence of the metabolic syndrome defined by the International Diabetes Federation among adults in the U.S. Diabetes Care 200528 2745-2749. (doi:10.2337/diacare.28.11.2745)

4 Ford ES, Giles WH \& Dietz WH. Prevalence of the metabolic syndrome among US adults: findings from the third National Health and Nutrition Examination Survey. Journal of the American Medical Association 2002287 356-359. (doi:10.1001/jama.287.3.356)

5 Misra A \& Khurana L. Obesity and the metabolic syndrome in developing countries. Journal of Clinical Endocrinology and Metabolism 200893 S9-30. (doi:10.1210/jc.2008-1595)

6 Hu G, Qiao Q, Tuomilehto J, Balkau B, Borch-Johnsen K \& Pyorala K. Prevalence of the metabolic syndrome and its relation to all-cause and cardiovascular mortality in nondiabetic European men and women. Archives of Internal Medicine 2004164 1066-1076. (doi:10.1001/ archinte.164.10.1066)

7 Isomaa B, Almgren P, Tuomi T, Forsen B, Lahti K, Nissen M, Taskinen MR \& Groop L. Cardiovascular morbidity and mortality associated with the metabolic syndrome. Diabetes Care 200124 683-689. (doi:10.2337/diacare.24.4.683)

8 Lakka HM, Laaksonen DE, Lakka TA, Niskanen LK, Kumpusalo E, Tuomilehto J \& Salonen JT. The metabolic syndrome and total and cardiovascular disease mortality in middle-aged men. Journal of the American Medical Association 2002288 2709-2716. (doi:10.1001/jama. 288.21.2709)

9 Lee NK, Sowa H, Hinoi E, Ferron M, Ahn JD, Confavreux C, Dacquin R, Mee PJ, McKee MD, Jung DY et al. Endocrine regulation of energy metabolism by the skeleton. Cell 2007130 456-469. (doi:10.1016/j.cell. 2007.05.047)

10 Ferron M, Wei J, Yoshizawa T, Del Fattore A, DePinho RA, Teti A, Ducy P $\&$ Karsenty G. Insulin signaling in osteoblasts integrates bone remodeling and energy metabolism. Cell 2010142 296-308. (doi:10.1016/j.cell.2010.06.003)

11 Confavreux CB. Bone: from a reservoir of minerals to a regulator of energy metabolism. Kidney International. Supplement 2011121 S14-S19. (doi:10.1038/ki.2011.25)
12 Oury F, Sumara G, Sumara O, Ferron M, Chang H, Smith CE, Hermo L, Suarez S, Roth BL, Ducy P et al. Endocrine regulation of male fertility by the skeleton. Cell 2011144 796-809. (doi:10.1016/j.cell.2011.02.004)

13 Kanazawa I, Yamaguchi T, Yamamoto M, Yamauchi M, Kurioka S, Yano S \& Sugimoto T. Serum osteocalcin level is associated with glucose metabolism and atherosclerosis parameters in type 2 diabetes mellitus. Journal of Clinical Endocrinology and Metabolism 200994 45-49. (doi:10. 1210/jc.2008-1455)

14 Saleem U, Mosley TH Jr \& Kullo IJ. Serum osteocalcin is associated with measures of insulin resistance, adipokine levels, and the presence of metabolic syndrome. Arteriosclerosis, Thrombosis, and Vascular Biology 201030 1474-1478. (doi:10.1161/ATVBAHA.110.204859)

15 Yeap BB, Chubb SA, Flicker L, McCaul KA, Ebeling PR, Beilby JP \& Norman PE. Reduced serum total osteocalcin is associated with metabolic syndrome in older men via waist circumference, hyperglycemia, and triglyceride levels. European Journal Endocrinology 2010163 265-272. (doi:10.1530/EJE-10-0414)

16 Tan A, Gao Y, Yang X, Zhang H, Qin X, Mo L, Peng T, Xia N \& Mo Z. Low serum osteocalcin level is a potential marker for metabolic syndrome: results from a Chinese male population survey. Metabolism 201160 1186-1192. (doi:10.1016/j.metabol.2011.01.002)

17 Bao Y, Zhou M, Lu Z, Li H, Wang Y, Sun L, Gao M, Wei M \& Jia W. Serum levels of osteocalcin are inversely associated with the metabolic syndrome and the severity of coronary artery disease in Chinese men. Clinical Endocrinology 201175 196-201. (doi:10.1111/j.1365-2265. 2011.04065.x)

18 Szulc P, Marchand F, Duboeuf F \& Delmas PD. Cross-sectional assessment of age-related bone loss in men: the MINOS study. Bone 200026 123-129. (doi:10.1016/S8756-3282(99)00255-0)

19 Szulc P, Claustrat B \& Delmas PD. Serum concentrations of $17 \beta-\mathrm{E}_{2}$ and 25-hydroxycholecalciferol (25OHD) in relation to all-cause mortality in older men - the MINOS study. Clinical Endocrinology 200971 594-602. (doi:10.1111/j.1365-2265.2009.03530.x)

20 Szulc P, Garnero P, Munoz F, Marchand F \& Delmas PD. Cross-sectional evaluation of bone metabolism in men. Journal of Bone and Mineral Research 200116 1642-1650. (doi:10.1359/jbmr.2001.16.9.1642)

21 Alberti KG, Eckel RH, Grundy SM, Zimmet PZ, Cleeman JI, Donato KA, Fruchart JC, James WP, Loria CM \& Smith SC Jr. Harmonizing the metabolic syndrome: a joint interim statement of the International Diabetes Federation Task Force on Epidemiology and Prevention; National Heart, Lung, and Blood Institute; American Heart Association; World Heart Federation; International Atherosclerosis Society; and International Association for the Study of Obesity. Circulation 2009120 1640-1645. (doi:10.1161/CIRCULATIONAHA.109.192644)

22 Holewijn S, den Heijer M, Swinkels DW, Stalenhoef AF \& de Graaf J. The metabolic syndrome and its traits as risk factors for subclinical atherosclerosis. Journal of Clinical Endocrinology and Metabolism 200994 2893-2899. (doi:10.1210/jc.2009-0084)

23 Confavreux CB, Szulc P, Casey R, Boutroy S, Varennes A, Vilayphiou N, Goudable J \& Chapurlat RD. Higher serum osteocalcin is associated with lower abdominal aortic calcification progression and longer 10-year survival in elderly men of the MINOS cohort. Journal of Clinical Endocrinology and Metabolism 201398 1084-1092. (doi:10.1210/jc. 2012-3426)

24 Bastos Goncalves F, Voute MT, Hoeks SE, Chonchol MB, Boersma EE, Stolker RJ \& Verhagen HJ. Calcification of the abdominal aorta as an independent predictor of cardiovascular events: a meta-analysis. Heart 201298 988-994. (doi:10.1136/heartjnl-2011-301464)

25 Wilson PW, Kauppila LI, O’Donnell CJ, Kiel DP, Hannan M, Polak JM \& Cupples LA. Abdominal aortic calcific deposits are an important predictor of vascular morbidity and mortality. Circulation 2001103 1529-1534. (doi:10.1161/01.CIR.103.11.1529)

26 Pi M, Chen L, Huang MZ, Zhu W, Ringhofer B, Luo J, Christenson L, Li B, Zhang J, Jackson PD et al. GPRC6A null mice exhibit osteopenia, feminization and metabolic syndrome. PLOS ONE 20083 e3858. (doi:10.1371/journal.pone.0003858) 
27 Iki M, Tamaki J, Fujita Y, Kouda K, Yura A, Kadowaki E, Sato Y, Moon JS, Tomioka K, Okamoto $\mathrm{N}$ et al. Serum undercarboxylated osteocalcin levels are inversely associated with glycemic status and insulin resistance in an elderly Japanese male population: Fujiwara-kyo Osteoporosis Risk in Men (FORMEN) Study. Osteoporosis International 201223 761-770. (doi:10.1007/s00198-011-1600-7)

28 Kanazawa I, Yamaguchi T, Tada Y, Yamauchi M, Yano S \& Sugimoto T. Serum osteocalcin level is positively associated with insulin sensitivity and secretion in patients with type 2 diabetes. Bone 201148 720-725. (doi:10.1016/j.bone.2010.12.020)

29 Kindblom JM, Ohlsson C, Ljunggren O, Karlsson MK, Tivesten A, Smith U \& Mellstrom D. Plasma osteocalcin is inversely related to fat mass and plasma glucose in elderly Swedish men. Journal of Bone and Mineral Research 200924 785-791. (doi:10.1359/jbmr.081234)

30 Confavreux CB, Borel O, Lee F, Vaz G, Guyard M, Fadat C, Carlier MC, Chapurlat R \& Karsenty G. Osteoid osteoma is an osteocalcinoma affecting glucose metabolism. Osteoporosis International 201223 1645-1650. (doi:10.1007/s00198-011-1684-0)

31 Oosterwerff MM, van Schoor NM, Lips P \& Eekhoff EM. Osteocalcin as a predictor of the metabolic syndrome in older persons: a populationbased study. Clinical Endocrinology 201378 242-247. (doi:10.1111/j. 1365-2265.2012.04391.x)

32 Oury F, Ferron M, Huizhen W, Confavreux C, Xu L, Lacombe J, Srinivas P, Chamouni A, Lugani F, Lejeune $\mathrm{H}$ et al. Osteocalcin regulates murine and human fertility through a pancreas-bone-testis axis. Journal of Clinical Investigation $2013 \mathbf{1 2 3}$ 2421-2433. (doi:10.1172/ JCI65952)

33 Bae SJ, Choe JW, Chung YE, Kim BJ, Lee SH, Kim HY, Koh JM, Kim HK \& Kim GS. The association between serum osteocalcin levels and metabolic syndrome in Koreans. Osteoporosis International 201122 2837-2846. (doi:10.1007/s00198-010-1504-y)
34 Yang R, Ma X, Pan X, Wang F, Luo Y, Gu C, Bao Y \& Jia W. Serum osteocalcin levels in relation to metabolic syndrome in Chinese postmenopausal women. Menopause 201320 548-553. (doi:10.1097/ GME.0b013e31828aa32d)

35 Confavreux CB, Levine RL \& Karsenty G. A paradigm of integrative physiology, the crosstalk between bone and energy metabolisms. Molecular and Cellular Endocrinology 2009310 21-29. (doi:10.1016/j. mce.2009.04.004)

36 Karsenty G \& Oury F. The central regulation of bone mass, the first link between bone remodeling and energy metabolism. Journal of Clinical Endocrinology and Metabolism 201095 4795-4801. (doi:10.1210/jc. 2010-1030)

37 Ferron M, Hinoi E, Karsenty G \& Ducy P. Osteocalcin differentially regulates $\beta$ cell and adipocyte gene expression and affects the development of metabolic diseases in wild-type mice. PNAS $2008 \mathbf{1 0 5}$ 5266-5270. (doi:10.1073/pnas.0711119105)

38 Ferron M, McKee MD, Levine RL, Ducy P \& Karsenty G. Intermittent injections of osteocalcin improve glucose metabolism and prevent type 2 diabetes in mice. Bone 201250 568-575. (doi:10.1016/j.bone.2011. 04.017)

39 Levinger I, Zebaze R, Jerums G, Hare DL, Selig S \& Seeman E. The effect of acute exercise on undercarboxylated osteocalcin in obese men. Osteoporosis International 201122 1621-1626. (doi:10.1007/s00198010-1370-7)

40 Schafer AL, Sellmeyer DE, Schwartz AV, Rosen CJ, Vittinghoff E, Palermo L, Bilezikian JP, Shoback DM \& Black DM. Change in undercarboxylated osteocalcin is associated with changes in body weight, fat mass, and adiponectin: parathyroid hormone (1-84) or alendronate therapy in postmenopausal women with osteoporosis (the PaTH study). Journal of Clinical Endocrinology and Metabolism 201196 E1982-E1989. (doi:10.1210/jc.2011-0587)

Received 10 July 2013

Revised version received 14 May 2014

Accepted 19 May 2014 